\title{
Contribuições da análise de discurso para a política pública de educação ambiental
}

\section{The contribution of discourse analysis to public policy on environmental education}

Andrea Quirino de Luca

USP

andreaqluca@gmail.com

Suzy Maria Lagazzi

Unicamp

slagazzi@gmail.com

Resumo: Esse artigo tem como perspectiva teórico-metodológica a Análise de Discurso de linha materialista, com base em autores como Michel Pêcheux, Louis Althusser e Eni Orlandi, que compõem a estrutura conceitual desse campo. Seu objetivo é buscar historicidade e lugares de significação de documentos referenciais da política pública federal de Educação Ambiental e, assim, trazer contribuições da análise de discurso para a área de saber da educação ambiental. Os documentos analisados são o Tratado de Educação Ambiental para Sociedades Sustentáveis e Responsabilidade Global, o Programa Nacional de Educação Ambiental (ProNEA), e o Programa de Formação de Educadoras(es) Ambientais: por um Brasil educado e educando ambientalmente para a sustentabilidade (ProFEA). Procuramos dar visibilidade aos pré-construídos e condições de produção que sustentam esse discurso, e terminamos o trabalho apontando quais noções materialistas podem contribuir com a discussão e apropriação dos documentos da política 
pública de educação ambiental pelos coletivos que se relacionam com essa política. As principais marcas e regularidades encontradas tratam de liberdade e autonomia, e as contribuições trazidas se relacionam com as noções de descentramento do sujeito, e com o entendimento de como são os processos discursivos e seus efeitos de sentido na produção da subjetividade, para afirmar que o sujeito não é fonte de seu dizer.

Palavras-chave: Educação Ambiental; Política Pública de Educação Ambiental; Análise de Discurso.

Abstract: This article uses the materialistic conception of the Discourse Analysis as a theoretical and methodological perspective, based on authors such as Michel Pêcheux, Louis Althusser and Eni Orlandi, who are the authors that make up the conceptual framework of this field. The main goal of this article is to seek historicity and significance in federal documents of public policy for Environmental Education, thus bringing the discourse analysis to contribute to the area of environmental knowledge and education. The documents analyzed are the Treaty of Environmental Education for Sustainable Societies and Global Responsibility, the National Environmental Education Program (ProNEA), and the Environmental Educator Training Program: for an educated Brazil and educating for environmental sustainability (ProFEA). We have tried to give visibility to the pre-built and production conditions that sustain these discourses, and finished our work pointing out which materialistic notions can contribute to the discussion and appropriation of public policy documents on environmental education for groups that relate to this policy. Major brands and regularities found dealing with freedom and autonomy, and the contributions made relate to the notion of decentralization of the subject to understand how the discursive process takes place and its effects on production of subjectivity so as to affirm that the subject is not the source of his own speech.

Keywords: Environmental Education; Public Policy on Environmental Education; Discourse Analysis.

Recebido em 24 de março de 2015. Aprovado em 25 de setembro de 2015. 


\section{Introdução}

Esta pesquisa tem como perspectiva teórico-metodológica a Análise de Discurso ${ }^{1}$ (AD) de linha francesa, e visa compreender, com base na análise materialista, a historicidade e lugares de significação da política pública federal de Educação Ambiental (EA) e, assim, trazer contribuições da $\mathrm{AD}$ para a área de saber da EA.

Realizar uma análise discursivo-materialista da política pública federal de EA (PPEA) significa pensar que essa análise não é uma leitura de conteúdo e que não se restringe a perguntar apenas do que tratam tais documentos, mas da relação desses documentos com suas condições de produção, dos efeitos de sentido produzidos na leitura, do que não foi dito, para que direções apontam, e assim, essa é uma importante contribuição.

Muitas análises são possíveis e, aqui, apresentamos um recorte que buscou analisar a liberdade e a autonomia como lugares de significação dos documentos analisados na questão do sujeito-de-direito. Acreditamos que a noção de descentramento do sujeito a que a $\mathrm{AD}$ dá visibilidade pode contribuir com discussões profícuas para reapropriação dos documentos pelas coletividades que se relacionam com a EA, e para que ocorram os deslocamentos desejados na direção de oposição à forma de produção atual.

Esse trabalho analisou os seguintes documentos: Tratado de Educação Ambiental para Sociedades Sustentáveis e Responsabilidade Global (BRASIL, 2005), Programa Nacional de Educação Ambiental (BRASIL, 2005), e Programa Nacional de Formação de Educadoras(es) Ambientais (BRASIL, 2006a).

A política pública federal de educação ambiental, enunciada pelo Órgão Gestor da política nacional de EA (PNEA), tem como atribuição e competência implementar programas e projetos desenhados no âmbito do Programa Nacional de EA (ProNEA), inspirados no Tratado de Educação Ambiental para Sociedades Sustentáveis e Responsabilidade Global (BRASIL, 2006b).

\footnotetext{
${ }^{1} \mathrm{~A}$ análise de discurso de linha francesa, desenvolvida inicialmente por Michel Pêcheux, com forte filiação ao materialismo de Louis Althusser, também é chamada de análise discursiva materialista. $\mathrm{O}$ analista busca na língua, materialidade do discurso, as marcas e regularidades para compreender o funcionamento discursivo do texto.
} 
O Tratado de EA é, assim, um documento referência para a EA no Brasil e foi construído com a participação de mais de 1.300 ONGs, com atuação em 108 países, durante o Fórum Internacional de ONGs e Movimentos Sociais, no contexto da Conferência da ONU Rio-92 (BRASIL, 2014; BRASIL, 2005; VIEZZER, 2004).

Esse documento é relevante para a EA, pois delimita, descreve, contextualiza e se opõe aos discursos que vinculam a EA ao desenvolvimento sustentável, abrindo caminho para práticas e reflexões por conta dessa fundamentação, inclusive para a PPEA (LUCA, 2013).

Esse artigo analisou a terceira edição do ProNEA (BRASIL, 2005). Em 2014, foi publicada a quarta edição (BRASIL, 2014), que inclui instrumentos legais e normativos da EA, cuja versão não foi objeto de análise deste trabalho.

Segundo o Órgão Gestor da PNEA, o ProFEA é um dos principais programas do Órgão Gestor, sendo instrumento da política pública de EA (BRASIL, 2006a; BRASIL, 2006b), e, devido a essa relevância, fez parte dos documentos analisados neste artigo.

Com base nas considerações aqui trazidas, apresentamos a análise de acordo com os procedimentos da $\mathrm{AD}$, buscando as principais marcas / regularidades na materialidade do texto para compreender seu funcionamento discursivo.

\section{A liberdade e a autonomia como regularidades - 0 efeito ideológico elementar}

Para compreendermos o efeito ideológico elementar, conceito chave para a AD materialista, e como ele afeta os documentos da política pública de EA aqui analisados, há de se falar das noções do materialismo histórico e dialético, e da interpelação dos indivíduos em sujeitos.

Um dos pontos de fundamentação do dispositivo teóricometodológico discursivo de perspectiva materialista, como já dito, é o descentramento do sujeito, que se funda no / com o materialismo histórico, sustentando a noção de que o sujeito não é fonte nem origem de sentido, mas sujeito à língua e à história, indivíduo interpelado a ser sujeito (ORLANDI, 2007).

A língua, por sua vez, não é transparente, simples meio de transmissão de sentidos pré-estabelecidos, mas suporte material sobre o qual se realiza a produção dos sentidos. Embora nos seja 
apresentada como transparente, a língua é opaca e demanda um investimento de leitura para que o modo da formulação, remetido às condições de produção do texto em questão, possa ser compreendido nas possibilidades de interpretação que comporta (ORLANDI, 1999; PÊCHEUX, 2009).

Ao lado do materialismo histórico, o materialismo dialético nos apresenta dois princípios básicos: (i) a primazia do real sobre seu conhecimento - a primazia do ser sobre o pensamento; e (ii) a distinção entre o real e o conhecimento - a distinção entre o ser e o pensamento. Jamais poderemos 'dar conta' de compreender o total do mundo, sempre teremos a perspectiva simbólica sobre o real (ALTHUSSER, 1986).

A ilusão do sujeito, que se coloca como centro de decisão, camufla a força coercitiva do senso comum e sustenta as relações de poder entre as pessoas, fazendo o sujeito acreditar na autonomia de sua vontade. Identidade, aqui, é entendida como uma configuração de sentidos em relação às condições de produção (ORLANDI, 1999).

O sujeito se constitui em posições de interpretação (posiçãosujeito), ou seja, estar sujeito à ideologia é a existência histórica de todo indivíduo, agente das práticas sociais. Essas práticas são reguladas por rituais e se inscrevem no seio da existência material de um aparelho ideológico - as práticas simbólicas como práticas materiais (ALTHUSSER, 1974). O imaginário e o ideológico encontram-se na mesma ordem, enquanto o simbólico está na ordem das palavras, sendo o discurso a ligação entre as duas ordens. $O$ discurso materializa o contato entre o ideológico e o linguístico (ORLANDI, 1999).

A ideologia é entendida como uma representação constitutiva da relação imaginária dos indivíduos com suas condições reais de existência, sendo um processo sem sujeito nem fim (ALTHUSSER, 1978). Porém, não há nenhuma relação que seja apenas de fora para dentro. Nos termos do assujeitamento, sempre a questão da identificação faz com que o sujeito se reconheça em sentidos para poder movimentar esse processo - só há ideologia pelo sujeito e para o sujeito, só há prática através de e sob uma ideologia (ALTHUSSER, 1986).

Diferente de concepções encontradas em outras áreas de saber, para a $\mathrm{AD}$, ideologia não é alienação ou falsa consciência. Ou seja, o sujeito nunca sai da ideologia para atingir a conscientização, não há um 'total' ou uma quantificação quando se trata de conscientização. 
Ideologia, assim, é a mediação entre os homens e suas condições materiais de existência, com relações de poder que regem a sociedade, elaboradas simbolicamente, num processo de produção de sentidos tidos como naturalizados e que, assim, passam a constituir o 'senso comum' (RODRÍGUEZ-ALCALÁ, no prelo; ORLANDI, 2008; PÊCHEUX, 2008).

De acordo com Althusser (1974, p. 95, grifos do autor):

Como todas as evidências, incluindo as que fazem com que uma palavra designe uma coisa ou possua uma significação (portanto incluindo as evidências da transparência da linguagem), esta evidência de que eu e você somos sujeitos - e que esse fato não constitui problema - é um efeito ideológico, o efeito ideológico elementar. Aliás, é próprio da ideologia impor (sem o parecer, pois que se trata de evidências) as evidências como evidências, que não podemos deixar de reconhecer, e perante as quais temos a inevitável reação de exclamarmos (em voz alta ou no silêncio da consciência): é evidente! É isso! Não há dúvida!

Segundo Pêcheux (2009), jamais poderemos encontrar um puro discurso científico separado de toda ideologia, já que todo discurso parte de um sujeito e todo sujeito é ideológico. Um método de análise, dentro de seus limites, deve procurar sua cientificidade, sua sistematicidade, para que não se torne $\mathrm{o}$ achar do pesquisador.

A perspectiva materialista pensa a língua como estrutura falha, no sentido de haver espaço para o movimento da estrutura, portanto os sentidos não são estáticos (LAGAZZI, 2010a). Forma material da língua, material como condições de produção: o discurso é a língua na história, significante na história. As ideias são atos materiais inseridos em práticas materiais, reguladas por rituais materiais. Os sujeitos e os sentidos se repetem e se deslocam (ORLANDI, 1999).

E todo ritual é falho, e esta falha é considerada uma abertura constitutiva, dando espaço para a deriva de significados. Portanto o deslocamento de significados não está no sujeito, mas na prática (que é simbólica). Essa é a possibilidade de transformação por conta do que já está posto (ORLANDI, 2007).

Nesse processo de identificação, que são processos que nos significam, assim a ideologia se caracteriza: "pela fixação dos conteúdos, pela impressão do sentido literal, pelo apagamento da materialidade da 
linguagem e da história, pela estruturação ideológica da subjetividade" (ORLANDI, 2008, p. 22).

Ser sujeito é sempre estar em relação ao outro, a unidade é sempre ilusória, é uma busca que nunca termina. Nesse caso, a identidade é uma configuração imaginária decorrente dos processos de identificação decorridos das condições de produção. E se toda a relação de sentido é pela diferença, a noção de valor é pela diferença sempre, já que as coisas apenas significam na relação, em 'relação a_'(ORLANDI, 2007).

Apesar de a AD não ter como objetivo explicar a interpelação do indivíduo em sujeito, ela pretende dar visibilidade às condições de produção dos sentidos e do conhecimento, quais seriam suas bases, quais seus pré-construídos, os processos de identificação dos sujeitos, seus efeitos de origem. Porque dando visibilidade ao que reafirma os sentidos estabilizados é que podemos ser tocados e mobilizados por outras possibilidades que levem a mudanças no social (ORLANDI, 2006).

A língua se constitui polissemicamente, marcando que o deslocamento de sentidos na relação com o mundo sempre é possível. A metáfora está na base do sentido, e o sentido é uma questão sempre aberta por ser uma questão filosófica. A semântica, enquanto lida com a significação, está lidando com a produção do conhecimento. Re-conhecer é conhecer o 'já-lá', ou seja, "algo fala antes, em outro lugar, (...) é o já dito que constitui todo dizer" (ORLANDI, 2006, p. 21).

Amemória discursiva ou interdiscurso (conjunto não representável de discursos), que relaciona-se com esse já-lá, sustenta a possibilidade do dizer, sua memória, representa a historicidade: "faz com que os sentidos sejam os mesmos e também que eles se transformem" (ORLANDI, 1999, p. 80).

O 'sempre-já-aí', diz Pêcheux (2009, p. 151), corresponde ao préconstruído da interpelação ideológica, que "fornece / impõe a realidade e seu sentido sob a forma da universalidade (o 'mundo das coisas'), (...)". $\mathrm{O}$ intradiscurso refere-se ao 'fio do discurso' de um sujeito: "o que eu digo agora, com relação ao que eu disse antes e ao que eu direi depois" (Ibid., p. 153). Digo "x" em determinadas condições de produção, quando poderia dizer " $y$ ", " $z$ " ou "w", e não poderia dizer " $m$ ", " $n$ " ou " $p$ ". $O$ dizer é regulado pelas condições de produção, pela posição do sujeito, pela memória do dizer. Nem apenas um sentido, nem qualquer sentido. Recortes dentro do possível.

Dessa forma, a noção de memória discursiva, que constitui o 'dizível', permite formulações de acordo com as posições discursivas, em 
seus contextos e condições de produção, sendo impossível a naturalidade do significante sempre investido por diferentes sentidos, dependendo das condições e posições discursivas. O sentido é sempre sentido para e não sentido em si (ORLANDI, 2007; PÊCHEUX, 2009).

Para Orlandi (2006), o sujeito se faz autor quando consegue formular, dentro do que é formulável, um lugar de interpretação, inscrevendo sua formulação no interdiscurso. E funcionamento discursivo é um recorte que está se realizando em uma memória do dizer, na própria relação da prática do dizer.

Assim, os indivíduos interpelados em sujeitos interpretam de suas posições discursivas, pelos efeitos da identificação, pelo equívoco constitutivo da ideologia: dinâmica e processo pelos quais os sujeitos se inscrevem em determinadas formações discursivas, que se interrelacionam entre si, e constituem as formações ideológicas (ORLANDI, 2006). Esse é o modo pelo qual o discurso 'faz sentido', e também é da ordem do que 'pode' e 'deve' ser dito de determinada posição.

Foi apenas a partir dos escritos de Louis Althusser (décadas de 1960 e 1970), que houve a possibilidade de se fundar um dispositivo que analisa o discurso, com volume teórico suficiente para permitir a compreensão dessa questão das identificações, formações ideológicas e posições-sujeito.

Porém, essa noção de descentramento do sujeito pelo inconsciente e pela ideologia continua ainda situada no terreno da $\mathrm{AD}$, sem que haja sensível trânsito entre as demais áreas. Portanto, esse conceito é mobilizado neste trabalho como possível elemento para a reflexão da política, não se tratando de um movimento de apontar uma falha estrutural, o que seria ingênuo de nossa parte, mas na direção da adição de um elemento que pode ser produtivo em abrir novas significações e possibilitar deslocamentos, que sempre são possíveis e, mais que isso, desejados.

Dessa forma, os próximos itens discutem na PPEA a questão da liberdade e da possibilidade de uma educação "capaz de emancipar os sujeitos". A análise pretende dar visibilidade para esse funcionamento como elemento de contribuição.

\section{O sentido em relação a}

Há um efeito de sentido que percorre todo o universo discursivo aqui analisado: a evidência / possibilidade da autonomia e da liberdade, e 
que a EA tem o papel de contribuir, estimular e realizar, pela participação social, essa 'emancipação'. Mas podemos perguntar: autonomia em relação a que / quem? Liberdade de quê / quem? Emancipar-se de quê /quem?

Como dito, a interpelação do indivíduo em sujeito pela ideologia, entendida como uma representação constitutiva da relação imaginária dos indivíduos com suas condições de existência, constitui posições de interpretação, ou posições-sujeito (ORLANDI, 2004).

A forma sujeito histórica, pela sua relação com o Estado-nação - e seus modos de funcionamento com a relação formal entre lógica / razão e direito, e seus mecanismos burocráticos e de administração - determina modos de individuação dos sujeitos (Ibid.).

Esse processo de individuação dos sujeitos pelo Estado, em conformidade com a ideologia burguesa, dá força a um discurso social de liberdade, autonomia, criatividade e originalidade, dando a ideia de que o sujeito é fonte e origem de sentidos (Ibid.), camuflando a força coercitiva do Estado e dos aparelhos ideológicos (ALTHUSSER, 1986).

Esse efeito ideológico elementar, em relação à forma de produção atual - o capitalismo - molda a forma de um "indivíduo livre de coerções e responsável, que deve, assim, responder como sujeito jurídico (sujeito de direitos e deveres), frente ao Estado e outros homens" (PÊCHEUX, 1999, p. 16).

Olhemos para alguns recortes que nos permitem ver esse funcionamento do discurso do Tratado de EA (BRASIL, 2005), abaixo. Parágrafo introdutório:

Nós, signatários, pessoas de todas as partes do mundo, comprometidas com a proteção da vida na Terra, reconhecemos o papel central da educação na formação de valores e na ação social. Comprometemo-nos com o processo educativo transformador através de envolvimento pessoal, de nossas comunidades e nações, para criar sociedades sustentáveis e eqüitativas. Assim, tentamos trazer novas esperanças e vida para nosso pequeno, tumultuado, mas, ainda assim, belo planeta (p. 57).

Introdução, último parágrafo:

Consideramos que a educação ambiental deve gerar, com urgência, mudanças na qualidade de vida e maior consciência de conduta pessoal, 
assim como harmonia entre os seres humanos e destes com outras formas de vida (p. 57).

Na seção Princípios da Educação para Sociedades Sustentáveis e Responsabilidade Global, segundo e décimo princípio (Ibid., p. 58):

A educação ambiental deve ter como base o pensamento crítico e inovador, em qualquer tempo ou lugar, em seu modo formal, não-formal e informal, promovendo a transformação e a construção da sociedade. A educação ambiental deve estimular e potencializar o poder das diversas populações, promovendo oportunidades para as mudanças democráticas de base que estimulem os setores populares da sociedade. Isto implica que as comunidades devem retomar a condução de seus próprios destinos.

No seção Plano de Ação, o sexto item (Ibid., p. 59): "Promover e apoiar a capacitação de recursos humanos para preservar, conservar e gerenciar o ambiente, como parte do exercício da cidadania local e planetária".

Se por um lado, o contexto de criação do Tratado de EA se significou como lugar de resistência e denúncia contra o sistema de produção capitalista, e isso é inegável, por outro lado, foca a mudança social no sujeito, tornando difícil o olhar sobre as condições de produção.

Esse foco da mudança social no sujeito pode ser visto nos trechos acima: "nós, signatários, pessoas (...) comprometidas com a proteção da vida na Terra"; "comprometemo- nos com o processo educativo transformador através de envolvimento pessoal"; "assim, tentamos trazer novas esperanças e vida para nosso (...) planeta"; "consideramos que a educação ambiental deve gerar, com urgência, mudanças na qualidade de vida e maior consciência de conduta pessoal"; "a educação ambiental deve ter como base o pensamento crítico (...), promovendo a transformação e a construção da sociedade"; "promover e apoiar a capacitação de recursos humanos para preservar, conservar e gerenciar o ambiente, como parte do exercício da cidadania local e planetária".

Com base nas considerações feitas aqui, e trazendo a primeira frase do documento:

"Este Tratado, assim como a educação, é um processo dinâmico em permanente construção. Deve portanto propiciar a reflexão, o debate e a sua própria modificação", perguntamo-nos se esse documento poderia, com modificações em sua materialidade, permitir a emergência de outros 
sentidos, numa direção de deslocar certas evidências produzidas pela sua forma histórica atual. Caso trouxesse suas condições de produção, como sua via da escrita, por exemplo, daria visibilidade a determinações históricas que relativizariam o efeito dessa escrita. É apenas nos vinculando ao viés histórico que poderemos mudar de terreno. Arrisco afirmar que é somente pelo caráter histórico que seria possível mudar a direção política da EA.

Assim, como o Tratado de EA é dito como inspiração para o ProNEA e o ProFEA, nesses outros documentos também encontramos o reforço da ideia da EA como forma de realizar a autonomia e a emancipação. Alguns recortes que nos permitem afirmar esse funcionamento são trazidos abaixo.

Na seção "Apresentação do ProNEA" (BRASIL, 2005, p.18, destaques nossos), temos:

E nesse contexto, em que os sistemas sociais atuam na promoção da mudança ambiental,_a educação assume posição de destaque para construir os fundamentos da sociedade sustentável, apresentando uma dupla função a essa transição societária: propiciar os processos de mudanças culturais em direção à instauração de uma ética ecológica e de mudanças sociais em direção ao empoderamento dos indivíduos, grupos e sociedades que se encontram em condições de vulnerabilidade em face dos desafios da contemporaneidade.

Na seção “Diretrizes” (Ibid., p. 34):

A participação e o controle social destinam-se ao empoderamento dos grupos sociais para intervirem, de modo qualificado, nos processos decisórios sobre o acesso aos recursos ambientais e seu uso. Neste sentido, é necessário que a educação ambiental busque superar assimetrias nos planos cognitivos e organizativos, já que a desigualdade e a injustiça social ainda são características da sociedade. Assim, a prática da educação ambiental deve ir além da disponibilização de informações.

Na seção “Objetivos” (Ibid., p. 39-41, nossos):

- Promover processos de educação ambiental voltados para valores humanistas, conhecimentos, habilidades, atitudes e competências que 
contribuam para a participação cidadã na construção de sociedades sustentáveis.

- Fomentar processos de formação continuada em educação ambiental, formal e não-formal, dando condições para a atuação nos diversos setores da sociedade.

- Contribuir com a organização de grupos -voluntários, profissionais, institucionais, associações, cooperativas, comitês, entre outros - que atuem em programas de intervenção em educação ambiental, apoiando e valorizando suas ações.

- Estimular as empresas, entidades de classe, instituições públicas e privadas a desenvolverem programas destinados à capacitação de trabalhadores, visando à melhoria $\mathrm{e}$ ao controle efetivo sobre o meio ambiente de trabalho, bem como sobre as repercussões do processo produtivo no meio ambiente.

- Criar espaços de debate das realidades locais para o desenvolvimento de mecanismos de articulação social, fortalecendo as práticas comunitárias sustentáveis e garantindo a participação da população nos processos decisórios sobre a gestão dos recursos ambientais.

No ProFEA (BRASIL, 2006a, p. 10-11, grifos nossos), na seção "Concepção Político-pedagógica, no Detalhamento dos Fundamentos da Formação de Educadoras(es) Ambientais":

Educação de Educadoras(es): A educação ambiental dentro de uma perspectiva libertária não busca o enquadramento dos educandos em uma norma mas sim a sua adesão a um processo autônomo de construção pessoal e participação na transformação de sua realidade social e ambiental. Desta forma o sujeito formado pela educação ambiental está além de uma pré- concepção formulada pelo educador(a), o sujeito formado é outro(a) educador(a) ambiental. O objetivo do(a) educador(a) ambiental libertário(a) é contribuir com a formação e o empoderamento de companheiras(os) de caminhada.

Intervenção educacional crítica e emancipatória: Atendendo aos dois fundamentos anteriores o processo de formação de educadoras(es) ambientais não consiste no acúmulo de conhecimentos, o eixo da aprendizagem não é uma "grade curricular" fechada, repleta de saberes pré- definidos, mas principalmente um processo de potencialização dos indivíduos e grupos para transformação de suas realidades. Esta 
potencialização passa pela realização de intervenções socioambientais reflexivas, educacionais, críticas e emancipatórias. Deve-se desenvolver um diálogo interpretativo a partir das distintas leituras da realidade vivenciada, da enunciação do futuro desejado e da formulação das distintas propostas, projetos, ações, estudos para enfrentamento das problemáticas (dentro do marco da complexidade) e transformação da realidade socioambiental no sentido da sustentabilidade e da felicidade.

A contribuição da noção do assujeitamento do indivíduo, com a produção do efeito ideológico elementar que resulta no centramento do sujeito como fonte dos sentidos e determinador da história, permite retomarmos o que Pêcheux (2009) define como pré- construído: o que tem um efeito de sentido, dado pela forma-histórica, do 'sempre já-aí'. Ou seja, a "interpelação ideológica que fornece-impõe a 'realidade' e seu 'sentido' sob a forma da universalidade (o 'mundo das coisas')..." (Ibid., p. 151).

Assim, trazendo a questão do assujeitamento com o consequente centramento do sujeito para esta análise do ProFEA, quando lemos (BRASIL, 2006a, p. 24, grifos nossos): "Tal ideia [práxis] decorre da ética da liberdade, do reconhecimento das diversidades, da autonomia no processo de aprendizagem (...) promover a construção do próprio processo de aprendizagem", observamos uma forte identificação com a questão da liberdade e autonomia do assujeitamento acima descrito.

Retornemos a um dos princípios da AD (ORLANDI, 2007; PÊCHEUX, 2009): ideologia é uma representação constitutiva da relação imaginária dos indivíduos com suas condições reais de existência, sendo um processo sem sujeito nem fim, que acontece de fora para dentro e de dentro para fora. Não há a possibilidade de ser sujeito fora de toda ideologia.

A questão do "promover a construção do próprio processo de aprendizagem" nos coloca a figura do sujeito como centro e origem. Portanto, ressalto a importância de conhecermos os pré-construídos que estão em funcionamento num determinado discurso, pois, lançando o olhar para as condições de produção, desprendemo-nos do sujeito e das soluções a ele imputadas, tendo a possibilidade da deriva e do deslizamento que essa visibilidade pode promover ao desnaturalizar as condições de produção como as únicas possíveis. $\mathrm{O}$ mundo pode ser diferente, as relações sociais podem ser outras, se os sujeitos se identificarem com outros sentidos. 
Ressaltar em processos ditos de educação ambiental práticas que possam dar visibilidade ao processo de assujeitamento e abrir a possibilidade de reflexão sobre os pré- construídos que nunca questionamos, pode contribuir com as direções que a política pública de EA aponta em seu discurso, que é a tentativa de romper com o positivismo.

\section{A noção de sujeito-de-direito como pré-construído}

O modo de produção capitalista funda suas relações jurídicas, baseado na noção de sujeito-de-direito, ou seja, o assujeitamento ao Estado Moderno impõe como forma-sujeito- histórica o sujeito-dedireito, que é aquele que responde por si, sob a afirmação de que "todos são iguais perante a lei"' - Constituição Federal (LAGAZZI, 1988). Pêcheux (2009), ao falar do efeito ideológico elementar, mostra que ele produz a evidência de que eu e você somos sujeitos. O poder do Estado ganha força no complexo jogo da individuação, no qual 'cada um' e 'todos' reafirmam o funcionamento jurídico. Imaginariamente somos cidadãos de um Estado constituído.

Dessa forma, o sujeito-de-direito foi se tornando uma noção constitutiva do caráter humano, do cidadão, ou seja, é como hoje nos reconhecemos socialmente. Porém, ao mesmo tempo em que nos 'vemos' como cidadãos únicos, o Estado 'fala' com todos ao mesmo tempo, na injunção jurídica da responsabilidade. Direitos e deveres são, então, a antinomia constitutiva de nossa sociedade (LAGAZZI, 2010b). Como sujeitos-de-direitos, acreditamos em nossa vontade e liberdade, acreditamos ser fonte dos sentidos por nós ditos. Os processos de individuação e o efeito ideológico elementar são elementos constitutivos das redes de tensões que vivemos e pelas quais nos significamos.

O capitalismo, sendo o modo de produção atual, tem como processo, então, a individuação do sujeito, que não é psicológica, mas política. E tem no Estado um espaço institucionalizado e significado pelo poder como espaço onde os sujeitos se inscrevem, trazendo a nós uma outra perspectiva dessa territorialidade de cidadãos, em nosso caso, brasileiros. Espaço gerenciado, espaço significado pela relação com o poder (ORLANDI, 2010a).

\footnotetext{
${ }^{2}$ Mais abaixo trazemos uma discussão sobre universalismo e, portanto, a invisibilidade das condições de produção.
} 
Como já dito, na constituição do sujeito temos a relação entre os termos de indivíduo, interpelação, forma-histórica, Estado, formação social, processo de individuação, posição- sujeito (ORLANDI, 2010b).

\section{O Homem que faz a história...}

Marx diz o seguinte (citado por ALTHUSSER, 1978, p. 70): "Os homens fazem sua própria história, mas não o fazem a partir de elementos livremente escolhidos, em circunstâncias escolhidas por eles, mas em circunstâncias que eles encontram imediatamente diante de si, dadas e herdadas do passado". Com base nisso, a compreensão materialista diz que "os homens fazem a história que é possível ser feita" (LAGAZZIRODRIGUES, 2006, p. 90). Há, portanto, uma crítica sobre o homemsujeito de sua história, que pode contribuir para que, cada vez mais, a educação ambiental busque nas condições de produção das relações sociais diferentes possibilidades de identificação para o sujeito.

Althusser (1978), em seu artigo "PROCESSO SEM SUJEITO NEM FIM (S)", diz que essa fórmula "processo sem sujeito" garante encontrar adversários sem dificuldades, já que a ideologia dominante diz justamente o inverso. Os homens são, sim, ativos na história como agentes das diferentes práticas sociais de produção e reprodução. Mas considerados como agentes não são sujeitos livres no sentido filosófico desse termo, pois atuam em determinadas formas de existência histórica das relações sociais de produção e reprodução. Ou seja, para ser agente, esse indivíduo é sujeito, reveste-se na forma-sujeito, que necessariamente ocupa as relações sociais (processos de trabalho, divisão e organização do trabalho, processo de reprodução, etc.).

Esse autor diz (Ibid., p. 68):

Foi com finalidades ideológicas precisas que a filosofia burguesa apoderou- se da noção jurídico-ideológica de sujeito, para dela fazer uma categoria filosófica no. 1, e para por a questão do Sujeito do conhecimento (o ego cogito, o sujeito transcedental kantiano ou husserliano, etc.) da moral, etc., e do Sujeito da história. (...) para ser materialista-dialética, a filosofia marxista deve romper com a categoria idealista de 'Sujeito' como Origem, Essência e Causa, responsável em sua interioridade por todas as determinações do 'Objeto' exterior (...), não pode haver Sujeito como Centro absoluto, como Origem radical, como Causa única. 
O descentramento do sujeito pelas reflexões materialistas, pela ideologia, e pelo inconsciente de Freud, ${ }^{3}$ constituem um gesto antipositivista que muda o terreno das reflexões sobre esse 'sujeito'. Se o homem faz a história que é possível ser feita (LAGAZZI- RODRIGUES, 2006), como dar abertura a essa não transparência dos processos sociais pela educação ambiental? Como pensar esse sujeito que, assujeitado a uma forma histórica de existência, quer atuar na direção de um deslocamento, de uma mudança, de um outro possível?

Reconhecemos, com base em análises (LUCA, 2013), o gesto de resistência trazido pelo Tratado de EA, pelo ProNEA e pelo ProFEA, em oposição ao movimento que há nos processos pedagógicos tradicionais que percorrem uma direção [política] no sentido de que o aluno 'entenda o mundo' já dado. Porém, insistimos na direção [política] de que os homens fazem a história que lhes é possível fazer, e essa pode ser uma das contribuições das reflexões do olhar aqui realizado pela 'lente' discursiva materialista, para tornar tal gesto de resistência mais profícuo.

Traçado aqui o 'lugar' do 'sujeito'visto de uma posição materialista - em oposição ao idealismo, seguimos para um aprofundamento da noção do sujeito-de-direito e da ideologia burguesa, tomando as reflexões de Haroche (1992), em seu livro Fazer Dizer, Querer Dizer.

\section{O sujeito responsável e o consenso}

Haroche (1992) problematiza a questão da 'Dupla Verdade' que ocorreu no século 13, que ocupava um lugar de contradição dentro da própria ordem religiosa dominante na época: de um lado a fé, de outro a razão. Anterior a esse momento, primava o princípio da não contradição, constitutivo das relações dos sujeitos com o saber. Havia total subordinação ao texto e ao dogma: tínhamos um 'sujeito religioso', totalmente submetido à ideologia cristã, assujeitado por práticas rituais a essa ordem religiosa, que se apoiava "tradicionalmente sobre o direito das pessoas mais do que sobre o direito centrado nos problemas estritamente econômicos" (Ibid., p. 57).

Com a expansão econômica, a questão do sujeito torna-se nevrálgica: há uma condução a uma redefinição do sujeito que, progressivamente,

\footnotetext{
3"Para Pêcheux, inconsciente e ideologia estão materialmente ligados", e têm uma relação comum com a língua, isso nos ajuda a entender o lugar da interpretação (ORLANDI, 2007, p. 63).
} 
torna-se um "sujeito à exação" (sujeito à cobrança), que vem substituir o sujeito religioso - uma sobredeterminação do jurídico sobre o religioso -, um sujeito que é religioso e ao mesmo tempo político, que é, mais ou menos, "determinador de seu próprio discurso" (Ibid., p. 59).

O século 13 já conhece o artesanal e o urbano, e se abre à ideia de lucro. O comércio se sedentariza e isso tem uma estreita ligação com os progressos da instrução, da escrita, e, logo, do progresso do aparelho jurídico. A partir já do século 11, há as reinvindicações dos direitos e liberdades pelos artesãos e comerciantes, e os camponeses lutando pelo reconhecimento de seus direitos, 'resgatando' sua liberdade. 'Todas essas reinvindicações revestem-se de um caráter fundamentalmente jurídico. Conduzem, inevitavelmente, à ideia de um 'sujeito-de-direito', tendo desde então direitos e deveres, um sujeito responsável por seus feitos e gestos" (Ibid., p. 68).

A transformação econômica, ideológica e necessariamente jurídica ainda no sistema feudal dá ao sujeito a possibilidade de se tornar livre mediante a possibilidade que lhe dá o senhor de se tornar um sujeito-à-exação - os camponeses se endividavam para comprar sua 'liberdade' (Ibid.).

A constituição de um Estado centralizador, o que também determinou o progresso do jurídico, configura um sujeito que se vê como único, responsável por si mesmo, podendo, entretanto, entrar para o anonimato de ser 'qualquer um'. A questão de relativizar uma verdade diminui muito a autoridade religiosa. Torna-se possível, por exemplo, um filósofo ${ }^{4}$ não se identificar ao assujeitamento religioso, ou seja, constituirse como um sujeito 'livre' pensador (Ibid.).

Sobre o dogma cristão, que descarta a autonomia do sujeito, Haroche (1992, p. 65) diz: "A crise do século XIII marca o início de um processo irreversível. Muito lentamente (...) desliza-se, não sem obstáculos, da dependência mais total ao dogma para um individualismo que, de imperceptível, triunfa no século XIX com o romantismo."

A riqueza da reflexão de Haroche nos permite compreender a questão do assujeitamento pela forma histórica de existência em nossa atualidade e, com base nisso, podemos avançarmos em outra direção.

\footnotetext{
${ }^{4}$ Aqui temos o pensamento de Averróis, que formula uma teoria política da religião, porém é somente no século 16 que Spinoza, no Tratado Teológico-político, formula a noção de política que se apoia na religião (HAROCHE, 1992).
} 


\section{A escrita não é neutra}

Vimos que a linguagem nunca poderá nos dar a realidade de uma forma neutra, imediata. Somos seres simbólicos instados a interpretar, e nossa relação com o mundo é mediada pelo simbólico. Os sentidos se produzem historicamente; não há uma linguagem neutra, e a ideia de clareza da língua já é evidência produzida pela ideologia. Procurando fundamentar as análises, trazemos a contribuição de ideias e conceitos do movimento estruturalista.

No livro Estruturalismo - antologia de textos teóricos, Coelho (1967, XII) diz: "O principal vício da ideologia burguesa é o naturalismo, a naturalização dos signos, a relação natural entre linguagem e a realidade". Ou ainda , citando Canguilhem (Ibid., idem): "o normal é normativo". Assim, o que temos funcionando nessa ideologia é que "não há realmente história, há apenas natureza" (Ibid., XIII, citando Roland Barthes).

O movimento estruturalista, ${ }^{5}$ abordagem que veio da área da linguística, cujo termo foi trazido inicialmente por F. Saussure $\mathrm{em}^{6} 1916$, circulou muito fortemente a partir de 1960 com nomes como Focault, Barthes, Althusser, Lacan, Milner, Miller, entre outros. É a partir disso que se torna possível a formação de uma teoria que reflete a linguagem não neutra num projeto de desnaturalização de signos, como é a $\mathrm{AD}$. Assim, a escrita, e seja qual for o objeto dessa escrita, situa seu autor numa determinada posição política e intelectual (Ibid.).

Sobre o que caracteriza o estruturalismo científico, Coelho (1967) diz que a língua é mais que as falas que cotidianamente se cruzam, porque há algo que teoricamente as precede e as fundamenta. E, complementando, afirma que:

É esta a situação da estrutura - a estrutura que apenas está presente nos seus efeitos e que inclui entre os seus efeitos a sua própria ausência, a

\footnotetext{
${ }^{5}$ Segundo Coelho (1967), o estruturalismo não é uma teoria fechada, homogênea e perfeita, mas possui um número considerável de conceitos que estão permanentemente sendo alterados num esforço admirável para distinguir ciência e ideologia. A AD se inscreve numa leitura estruturalista do discurso, leitura materialista, porém, considera a estrutura como suporte material, funcionando enquanto discurso.

${ }^{6}$ Linguista e filósofo suiço.
} 
estrutura como algo que põe o sujeito em cena e lhe atribui um papel, sem nunca se tornar visível na plena evidência dessa cena, a estrutura como estruturalidade.

O estruturalismo toma como questão radical a afirmação 'não há um centro' (nem Deus - discurso religioso - nem a inefabilidade da essência humana - humanismo). O sentido não é origem absoluta de um significado transcendental, mas "deve esperar ser dito ou escrito para se habitar a si próprio" (Ibid., XLV, citando o filósofo Jacques Derrida). Consciência, assim, não tem interior, "ela é apenas o exterior de si mesma, (...) consciência é sempre consciência de qualquer coisa (COELHO, 1967, XLI).

E sobre a afirmação 'não há um centro', podemos dizer que as feridas narcisísticas ${ }^{7}$ assinalam importantes momentos da história ocidental: com Copérnico, o homem deixou de estar no centro do universo; com Darwin, deixou de ser o centro do reino animal; com Marx, deixou de ser o centro da história (sujeito descentrado pela ideologia); e com Freud, deixou de ser o centro de si mesmo (descentrado pelo inconsciente) (COELHO, 1967).

\section{A questão do 'bem comum'}

Tomando as afirmações trazidas acima: 'não há um centro' e 'consciência é sempre consciência de qualquer coisa', continuamos nossa análise trazendo a questão do universalismo.

O primeiro princípio do Tratado de EA afirma: "a educação é um direito de todos; somos todos aprendizes e educadores". Aqui seria uma possível paráfrase que a educação é obrigatoriamente para todos, é o necessariamente desejável para todos, todas as pessoas podem e devem ter a educação. Mas como seria nomear todos?

Ainda podemos nos perguntar: há as mesmas condições para que todos tenham direito à educação? A educação é uma possibilidade de mudança positiva para todos? Que relações de educação são essas que permitem as mudanças? Esse direito à educação está próximo do significado de devemos ter educação?

Essa intercambialidade do sujeito, reafirmada pelo Estado e pela

${ }^{7}$ Mencionadas inicialmente por Freud. 
ideologia jurídica, que historicamente foi tomando o lugar da ordem religiosa que foi se enfraquecendo (do séc. 13 ao 16), determina uma ambiguidade que configura uma marca específica do sujeito que se vê como um ser único, mestre e responsável por si mesmo, podendo, a qualquer momento, ser 'qualquer um', caindo na clandestinidade (HAROCHE, 1992).

O manifesto humanista da ideologia burguesa do século 19, que anuncia a liberdade do indivíduo conjugada ao amor à pátria, apoia-se no rigor e transparência da letra, da cifra, e estabelece a relação do Direito e do saber: o direito ao saber, à inteligibilidade, à abertura, tudo isso nascido da troca e da expansão econômica. A letra é, com efeito, "um dos imperativos necessários à expansão econômica (...). O que não significa que ela se torne efetiva e igualmente inteligível para "qualquer sujeito"', bastando observar como isso se dá nas tensas relações sociais de poder em nossa sociedade (HAROCHE, Op. cit., p. 84).

O processo de generalização e a busca do consenso, constitutivo do funcionamento jurídico, é dito por Lagazzi (2010b, p. 79): "Tudo se passa, portanto, como se o Estado, anulando as classes, anulasse com isso a própria contradição, se erigindo em lugar da não contradição, onde se realiza o 'bem comum'”.

Ainda em Lagazzi (Op. cit., p. 83), temos:

Em sua abrangência imaginariamente irrestrita, o 'bem comum' aparece como causa sem falha da democracia liberal, formulação pacificadora da sociedade capitalista. A noção de conciliação, significada em meio a ideais democráticos, fica necessariamente atravessada pela idealização do 'bem comum', numa derivação do consenso que se diz concordância, conformidade, acordo. Ficamos todos significados como sujeitos de vontades equivalentes, vontades que se materializam em trocas.

Com base nessa discussão sobre o universalismo' (do 'bem comum'), da educação para todos, insistimos que é somente considerando as condições de produção, a história, que podemos deixar de reafirmar

\footnotetext{
${ }^{8}$ Suzy Lagazzi, neste artigo, traz a obra de Márcio Naves (2000), 'Marxismo e Direito', em que este estuda Evgeni Pachukanis (1924).

${ }^{9}$ Um outro exemplo de afirmação desse cunho: "a justiça é igual para todos".
} 
essa fundamentação jurídica que responsabiliza o indivíduo e que necessariamente não relativiza, e, assim, perversamente, afirma ainda mais a individuação e mantém tais sentidos estabilizados.

Para sairmos da generalização, podemos nos perguntar: nessa questão da educação, o que é de fato importante dizer para deslocar? Nesse momento, retomamos de passagem a noção de autoria vinculada à educação, que é a possibilidade de nos responsabilizarmos por sentidos. A função-autor na educação, trazida no capítulo anterior, voltará a ser discutida no sexto capítulo

\section{Individualidade e coletividade, local e planetário}

O movimento desta análise foi compreender a questão do descentramento do sujeito do campo da AD como contribuição para a área de EA, assim como o sentido está sempre em relação a_. Como a questão do sentido é sempre aberta, a relação entre significado e significante está sempre em deslize e re-configuração, e pode nos permitir compreender questões da ordem da historicidade (LAGAZZI-RODRIGUES, 2006).

Assim, analisando a noção de espaço e de mundo no Tratado de EA, antes da seção "Introdução", temos o seguinte parágrafo (grifos nossos):

Este Tratado, assim como a educação, é um processo dinâmico em permanente construção. Deve portanto propiciar a reflexão, o debate e a sua própria modificação. Nós signatários, pessoas de todas as partes do mundo, comprometidos com a proteção da vida na Terra, reconhecemos o papel central da educação na formação de valores e na ação social. Nos comprometemos com o processo educativo transformador através do envolvimento pessoal, de nossas comunidades e nações para criar sociedades sustentáveis e eqüitativas. Assim, tentamos trazer novas esperanças e vida para nosso pequeno, tumultuado, mas, ainda assim, belo planeta.

Local e planetário, natureza e universo, meio ambiente, essas são referências diretas ao espaço / mundo. A noção de espaço muitas vezes está relacionada com a ideia de coletivo, de ambiente comum, onde ocorrem as relações dos seres humanos, num entendimento de vínculo constitutivo: "Nós signatários, pessoas de todas as partes do mundo, comprometidos com a proteção da vida na Terra, (...) Nos comprometemos com o processo educativo transformador através 
do envolvimento pessoal, de nossas comunidades e nações para criar sociedades sustentáveis e eqüitativas". Ou Ainda: "consciência ética sobre todas as formas de vida com as quais compartilhamos este planeta (...)".

$\mathrm{Na}$ seção de "Princípios", citamos quatro deles (princípios número três, cinco, sete e dezesseis):

- A educação ambiental é individual e coletiva. Tem o propósito de formar cidadãos com consciência local e planetária, que respeitem a autodeterminação dos povos e a soberania das nações.

- A educação ambiental deve envolver uma perspectiva holística, enfocando a relação entre o ser humano, a natureza e o universo de forma interdisciplinar.

- A educação ambiental deve tratar as questões globais críticas, suas causas e inter-relações em uma perspectiva sistêmica, em seus contexto social e histórico. Aspectos primordiais relacionados ao desenvolvimento e ao meio ambiente tais como população, saúde, democracia, fome, degradação da flora e fauna devem ser abordados dessa maneira.

- A educação ambiental deve ajudar a desenvolver uma consciência ética sobre todas as formas de vida com as quais compartilhamos este planeta, respeitar seus ciclos vitais e impor limites à exploração dessas formas de vida pelos seres humanos.

Podemos reconhecer uma regularidade muito significativa neste documento, considerando os trechos acima citados, sobre um funcionamento conjuntivo que une noções contraditórias, como se fosse algo da ordem do ordinário: individualidade e coletividade, por exemplo, "a educação ambiental é individual e coletiva" (terceiro princípio acima citado), e é local e planetária.

Outro trecho que contém esse funcionamento conjuntivo está na "Introdução" (grifos nossos): "Ela [a EA] estimula a formação de sociedades socialmente justas e ecologicamente equilibradas, que conservam entre si relação de interdependência e diversidade. Isso requer responsabilidade individual e coletiva a nível [sic] local, nacional e planetário".

A tensão que há entre noções de individualidade e coletividade está na contradição constitutiva dessa relação, não é algo corriqueiro, é, diferente disso, algo muito conflituoso. Termos como coletividade e comunidade estão relacionados com cooperação e diálogo. Essa questão, 
que precisa ter explicitadas as relações de forças que a constituem, pode, além dos trechos acima citados (sobretudo o princípio dezesseis), ser vista no sexto, oitavo e no décimo terceiro princípio:

- A educação ambiental deve estimular a solidariedade, a igualdade e o respeito aos direitos humanos, valendo-se de estratégias democráticas e interação entre as culturas.

- A educação ambiental deve facilitar a cooperação mútua e eqüitativa nos processos de decisão, em todos os níveis e etapas.

- A educação ambiental deve promover a cooperação e o diálogo entre indivíduos e instituições, com a finalidade de criar novos modos de vida, baseados em atender às necessidades básicas de todos, sem distinções étnicas, físicas, de gênero, idade, religião, classe ou mentais.

O décimo segundo princípio cita conflito: “A educação ambiental deve ser planejada para capacitar as pessoas a trabalharem conflitos de maneira justa e humana". Pergunto, assim, qual a concepção de humano que sustenta esse dizer? Como seria o tratamento desses conflitos? Seria a noção de igualdade que está vigorando nesse dizer?

Colocar em evidência as relações de poder e as diferenças entre humanos, com suas específicas condições de produção, pode contribuir para esse enfrentamento.

Termos como educação, igualdade, solidariedade, direitos, são nomeações muito estabilizadas, produzem evidências que acabam por nos 'engolir', ficamos colados em noções já esvaziadas e isso atravanca outras noções muito pertinentes que o Tratado de EA e o ProNEA abordam e trabalham. Ou seja, há memória nesses termos, produzida historicamente, e estamos filiados a tais sentidos, não nos perguntamos mais quem / quais são eles. Fazer um certo gesto sobre essa memória pode deslocá-la.

Não basta a intenção assertiva. A materialidade do documento, sua redação, deve ser sempre objeto de questionamentos e análise, para que haja a saída do lugar comum em que tantos documentos oficiais, políticas e leis se perdem, sustentando uma certa verborragia.

A linguagem, como já dito, não é neutra ou natural, e a evidência (produzida) de que é clara, transparente e objetiva, apaga o político e fortalece o positivismo. Nenhum discurso está apartado 
da sociedade que o produz e de seus processos histórico-sociais. A relação é constitutiva. E todo processo discursivo pertence a uma determinada formação discursiva que, por sua vez, faz parte de uma formação ideológica (ORLANDI, 1987). E é nessa direção que esta análise buscou contribuir.

\section{Considerações finais}

Neste percurso analítico pudemos observar como é forte a noção de sujeito-de-direito no discurso da política pública de EA do Brasil, o que configura o imaginário da educação de forma geral, na responsabilização do(s) sujeito(s), e também na ideia de que só depende de cada um galgar e subir na vida, aprender, resolver, participar, mudar. O indivíduo, neste discurso é, então, livre de coerções e responsável.

A noção de educação como ação política é oriunda de uma linha marxista que faz referência à frase: "O homem faz a história...", mas num recorte considerado, sob a perspectiva materialista, como idealista, pois não se ancora na noção de descentramento do sujeito. Ou seja, sob a perspectiva materialista, os homens fazem a história que é possível ser feita - história sem sujeito nem fim.

Afirmamos, assim, a importância de discutirmos a noção de sujeito-de-direito que é sustentada pelos documentos, que fortalece a ideia de autonomia e liberdade dos cidadãos, e confrontá-la com discussões coletivas de reapropriação do documento e consequentes modificações deste. Acreditamos que isso possa contribuir para abrir processos de significação em outras direções bastante produtivas. Consideramos de fundamental importância que noções como as de democracia, sujeito político e educação ambiental continuem abertas, sobre as quais é sempre importante questionar.

$\mathrm{Na}$ "intenção' ${ }^{10}$ que tem a política pública de resistir à forma de produção atual, que é o capitalismo, a responsabilização do sujeito não contribui para um deslocamento aí desejado. Assim como pudemos observar que é por meio da história que se abre a possibilidade da mudança de terreno, a materialidade dos documentos poderia contribuir com a abertura para novos sentidos com base nas condições de produção e no viés histórico. É desconstruindo as evidências do humanismo e do

\footnotetext{
${ }^{10} \mathrm{~A}$ intenção do sujeito se relaciona com o efeito ideológico elementar.
} 
positivismo que se abre a possibilidade de um outro modo de significar, pela história.

O universalismo que fala com todos e com cada um, e com ninguém, apaga as relações de poder e as condições de produção, abrindo espaço na direção da individuação, e não de sentidos de coletividade.

Buscar a historicidade por meio de certa análise discursiva é buscar dar visibilidade aos seus pré-construídos, para compreender melhor as condições de produção de sentidos, o que é reafirmado, em que direções esses sentidos trabalham. Dessa forma, pelo entendimento do que reafirma os sentido estabilizados é que podemos ter a possibilidade de nos mobilizarmos em direção a outros sentidos, ressignificações que levem à mudança no campo social (ORLANDI, 2006).

Assim, acreditamos que a contribuição da AD para a formação de educadores ambientais é a possibilidade de dar visibilidade às questões do assujeitamento, individuação, interpretação como efeito ideológico e pré-construídos que funcionam na sustentação da produção e reprodução das relações sociais em nossas condições de existência, porque a transformação passa pela reprodução, e tem na falha [constitutiva] espaço para um outro possível.

Esse deslize para o outro possível, pode, ao abrir-se para noções estas materialistas, contribuir para uma mudança de terreno, apontar para direções profícuas quanto às questões da metáfora, da polissemia, de coisas sem sentido que passam a ter sentido, de ressignificações possíveis aos sujeitos que fazem a história que é possível ser feita, de acordo com suas condições de existência.

\section{Referências}

ALTHUSSER, L. Ideologia e aparelhos ideológico do Estado. Trad. Joaquim José de Moura Ramos. Porto: Editorial Presença, 1974.

. Observação sobre uma categoria: "PROCESSO SEM SUJEITO NEM FIM(S)". In: ALTHUSSER, L. Posições I. Rio de Janeiro: Graal, 1978.

. Materialismo histórico e materialismo dialético. Trad. Elisabete A. Pereira dos Santos. 2ed. São Paulo: Global, 1986.

BRASIL. ProNEA / Educação Ambiental por um Brasil Sustentável ProNEA, Marcos Legais e Normativos. 4ed. Brasília: Ministério do Meio 
Ambiente; Ministério da Educação. 2014. Disponível em: <http://www. mma.gov.br/publicacoes/educacao-ambiental/category/98-pronea $>$. Acesso em: 21 mar. 2015.

.ProFEA - Programa de formação de educadores(as) ambientais. Por um Brasil educado e educando ambientalmente para a sustentabilidade. Brasília: Ministério do Meio Ambiente/Diretoria de Educação Ambiental. 2006a. Disponível em: <http://www.cdcc.sc.usp.br/CESCAR/Material_ Didatico/ProFEA.pdf>. Acesso em: 21 mar. 2015.

. Portfólio do Órgão Gestor da Política Nacional de Educação Ambiental. Brasília: Série Documentos Técnicos, n. 7, Brasília, DF, 2006. . ProNEA - Programa Nacional de Educação Ambiental. Ministério do Meio Ambiente, Departamento de Educação Ambiental; Ministério da Educação, Coordenação Geral de Educação Ambiental. 3 ed. Brasília: MMA, DF, 2005. Disponível em: <http://portal.mec.gov.br/secad/arquivos/ pdf/educacaoambiental/pronea3.pdf $>$. Acesso em: 21 mar. 2015.

COELHO, Eduardo Prado. Introdução a um pensamento cruel: estruturas, estruturalidades e estruturalismos. In: COELHO, E. P. (Org.). Estruturalismo - Antologia de textos teóricos. Sem local definido: Livraria Martins Fontes Editora, 1967.

HAROCHE, Claudine. Fazer Dizer, Querer Dizer. Trad. Eni Pulcinelli Orlandi. São Paulo: Hucitec, 1992.

. Texto e autoria. In: ORLANDI, E. P.; LAGAZZI-RODRIGUES, S. (Org.). Introdução às ciências da linguagem-Discurso e textualidade. Campinas: Pontes, 2006.

LAGAZZI, Suzy Maria. O desafio de dizer não. Campinas: Pontes, 1988.

. The social in scene in significant materiality, Acta Scientiarum - Language and Culture, v. 32, n. 2, p. 153-161. 2010a.

. O confronto político urbano administrado na instância jurídica. In: ORLANDI, E. P. (Org.). Discurso e políticas públicas urbanas - a fabricação do consenso. Campinas: RG, $2010 \mathrm{~b}$.

LAGAZZI-RODRIGUES, Suzy Maria. A discussão do sujeito no movimento do discurso. Tese (Doutorado em Linguística) - Instituto de Estudos da Linguagem, Universidade Estadual de Campinas, 1998.

LUCA, Andrea Quirino. Uma análise de discurso da política pública federal de educação ambiental. Tese (Doutorado em Ciência Ambiental) 
- Ciência Ambiental, Universidade de São Paulo, São Paulo, 2013.

NAVES, Márcio B. Marxismo e direito - um estudo sobre Pachukanis. São Paulo: Boitempo, 2008.

ORLANDI, E. P. A linguagem e seu funcionamento: as formas do discurso. Campinas: Pontes, 1987.

Pontes, 1999.

. Análise de discurso - princípios e procedimentos. Campinas:

. Cidade dos Sentidos. Campinas: Pontes, 2004.

. Análise de Discurso. In: ORLANDI, E. P.; LAGAZZIRODRIGUES, S. (Org.). Introdução às ciências da linguagem - Discurso e textualidade. Campinas: Pontes, 2006.

. Interpretação - autoria, leitura e efeitos do trabalho simbólico. 5ed. Campinas: Pontes, 2007.

. Discurso e Texto: formulação e circulação dos sentidos. 3ed. Campinas: Pontes, 2008.

. (Org.) Os sentidos de uma estátua: espaço, individuação, acontecimento e memória. Entremeios: revista de estudos do discurso. v.1, n.1, jul., 2010a.

. Discurso e políticas públicas urbanas - a fabricação do consenso. Campinas: RG, $2010 \mathrm{~b}$.

PÊCHEUX, M. Semântica e Discurso: uma crítica à afirmação do óbvio. Trad. Eni P. Orlandi et al. 4ed. Campinas: Unicamp, 2009.

. O discurso: estrutura ou acontecimento. Trad. Eni P. Orlandi. 5ed. Campinas: Pontes, 2008.

RODRÍGUEZ-ALCALÁ, C. Ambiência e Linguagem na Produção Simbólica do Espaço Urbano: a distinção público / privado e a percepção do movimento. Atmosphäre und Sprache in der symbolischen Produktion des städtischen Raumes: die Unterscheidung öffentlich/privat und die Wahrnehmung von Bewegung. In: THIBAUD, J.-P.; KAZIG, R. Hg. (Ed.). Städtische Atmosphären. Bielefel: Bielefel, (no prelo).

VIEZZER, M. L. Somos Todos Aprendizes - Lembranças da construção do Tratado de Educação Ambiental. Paraná, Toledo, 2004. Disponível em: <http://www.ecomarapendi.org.br/REBEA/Arquivos/aprendizes. htm>. Acesso em: 21 mar. 2015. 